\title{
Paediatrics Supratentorial Extraventricular Ependymoma
}

Vinayak Raje, Sunil Yadav, Pandurang Barve ${ }^{*}$, Devdutta Patil and Bhushan Shinde

Krishna Institute of Medical Scinces, Karad, Maharashtra, India

*Corresponding author: Pandurang Barve, Krishna Institute of Medical Scinces, Karad, Maharashtra, Tel: 9981583921; E-mail: pandurangexams@gmail.com Rec Date: Sep 30, 2015; Acc Date: Sep 30, 2015; Pub Date: Oct 02, 2015

Copyright: @ 2015 Raje V, et al. This is an open-access article distributed under the terms of the Creative Commons Attribution License, which permits unrestricted use, distribution, and reproduction in any medium, provided the original author and source are credited

\begin{abstract}
Introduction: Majority of ependymomas are infratentorial and intraventricular. Supratentorial and purely cortical extraventricular ependymomas are extremely rare and only six cases were reported so far.
\end{abstract}

Case report: We report a 12-year-old female with right parieto occipital ependymoma. She had complete excision of the lesion.

Conclusion: Pure cortical, supratentorial extraventricular ependymoma in paediatrics age group is a rarity.

Keywords: Cortical; Ependymoma; Extraventricular; Paediatrics

\section{Introduction}

Ependymomas are usually infratentorial and a third of the ependymomas are supratentorial. Of the supratentorial ependymomas, extraventricular tumors account for 50\% [1] the majority of them are in the vicinity of the ventricles and have some connection to ventricular margins. Purely extraventricular ependymomas with no connection to ventricular lining are very rare and only six cases were reported in the literature so far [1-3]. We report one pediatric case of supratentorial extraventricular ependymoma.

\section{Case Report}

A 12 year old girl presented with one episode of seizure for which she was treated and investigated in form of contrast computerized tomography. CT brain which showed a right parieto-occipital peripherally placed lesion with perilesional edema and hypodense space medialy (Figure 1).

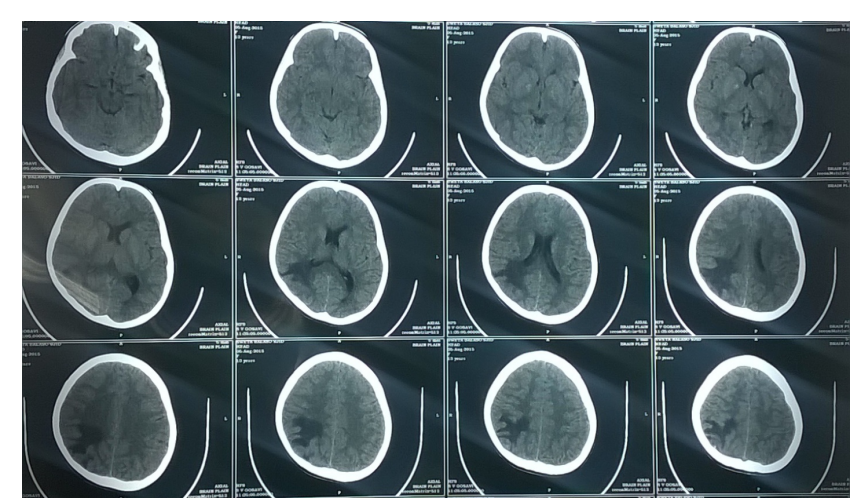

Figure 1: Right parieto occipital hypodense lesion with periiesional edema
MRI of the Brain Contrast study was done suggestive of well defined, lobulated, oval intra-axial enhansing space occupying lesion in the cortical, subcortical aspect of the right parieto occipital region. It showed solid as well as cystic component in it (Figure 2).

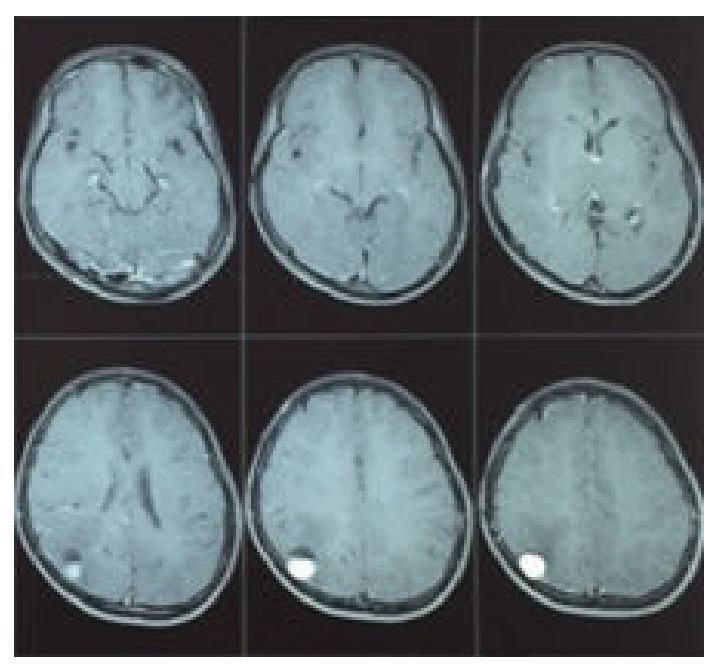

Figure 2: MRI showing right parieto occipital enhansing space occupying lesion

Right sided parieto occipital craniotomy done.Dura opened, brain bulg present. Greyish white tumour coming out. Tumour was moderately vascular and of firm to soft consistancy. Compiete excision of tumour done. Clear fluid gushed out after delivering the last part of tumour (Figure 3). The tumor had no connection to the ventricular ependymal lining. Margins were well defined. The postoperative period was uneventful and she recovered well. Histopathogy of the excised tumor showed that the tumour was composed of round neoplastic cells arranged in rossets, clusters and small sheets. Prominent perivascular rossets with fibrillary structures oriented towards the blood vessels are noted. At places the tumor appears cellular and compact. The cells are round to oval having round to oval delicate vesicular nuclei with 
Citation: Raje V, Yadav S, Barve P, Patil D, Shinde B (2015) Paediatrics Supratentorial Extraventricular Ependymoma. Brain Tumors Neurooncol

Page 2 of 2

inconspicious nucleoli and moderate amount of eosinophilic cytoplasm (Figure 4). Some mitotic activity is noted. The neoplastic cells are separated by thin fibrovascular stroma. Immunohistochemistry of the excised tumor done for confirmation and grading. On microscopic examination EMA revealed to be strongly positive showing paranuclear dot positivity. MIB-1(Ki-67) is and $8-10 \%$. Diagnosis of an ependymoma of World Health Organization (WHO) grade III was made.

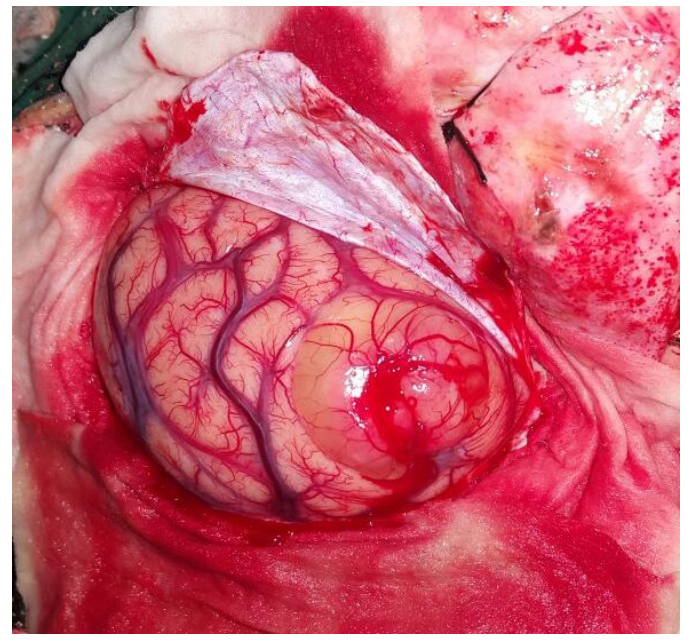

Figure 3: Intra-operative image of right parieto-occipital ependymoma

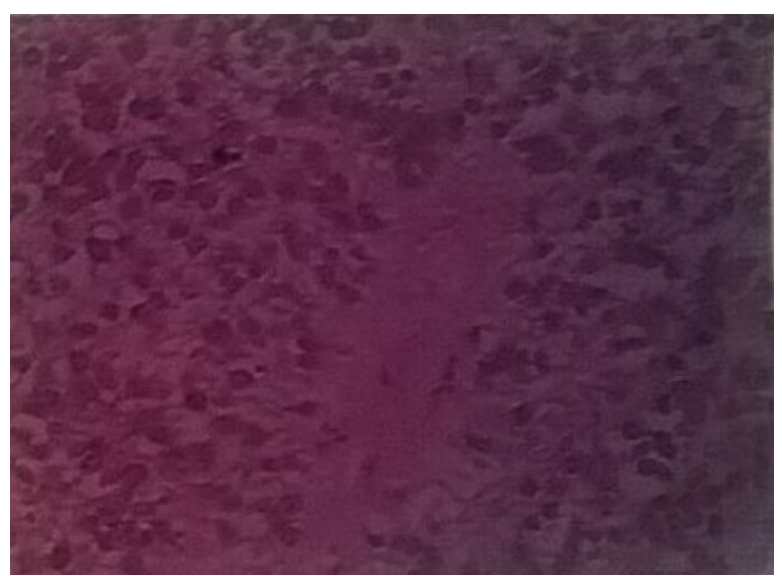

Figure 4: Microscopic Examination showing round neoplastic cells arranged in rossets, clusters and small sheets. Prominent perivascular rossets with fibrillary structures

\section{Discussion}

Till date, only six cases of purely cortical supratentorial extraventricular ependymomas have been reported in literature [1-3] Supratentorial ependymomas represent a subgroup with a comparatively better prognosis when compared to infratentorial ependymomas. This may be related to the fact that total resection is more commonly achieved in supratentorial tumors. Adults have a better five-year survival than children. Children less than 2.5 years of age, have a significantly worse prognosis than older children [4]. In the young children, five-year survival is $22.40 \%$ as compared to $60.75 \%$ in older children [4]. Prognosis in children older than five years is same as that of adults [4]. Outcome can be better correlated when age at diagnosis is considered along with extent of surgical resection [4]. The need for postoperative adjuvant therapy has been controversial for supratentorial ependymomas. In general, it is considered safe to observe the patient when postoperative CT or MR shows gross total excision, particularly when the tumor is of low grade [5]. Even in the presence of recurrence some authors suggest total excision by a second operation. Thus, the option for postoperative radiation is only for high-grade tumors and tumors in locations where total excision is not possible [5].

\section{Conclusion}

Pure cortical supratentorial extraventricular ependymoma in paediatric age group is a rarity.

\section{References}

1. Roncaroli F, Consales A, Fioravanti A, Cenacchi G (2005) Supratentorial cortical ependymoma: report of three cases. Neurosurgery 57: E192.

2. Saito T, Oki S, Mikami T, Kawamoto Y, Yamaguchi S, et al. (1999) [Supratentorial ectopic ependymoma: a case report]. No Shinkei Geka 27: 1139-1144.

3. Lehman NL, Jorden MA, Huhn SL, Barnes PD, Nelson GB, et al. (2003) Cortical ependymoma. A case report and review. Pediatr Neurosurg 39: 50-54.

4. Pollack IF, Gerszten PC, Martinez AJ, Lo KH, Shultz B, et al. (1995) Intracranial ependymomas of childhood: long-term outcome and prognostic factors. Neurosurgery 37: 655-666.

5. Palma L, Celli P, Mariottini A, Zalaffi A, Schettini G (2000) The importance of surgery in supratentorial ependymomas. Long-term survival in a series of 23 cases. Childs Nerv Syst 16: 170-175. 